\title{
Association of chemotherapy with survival in stage II colon cancer patients who received radical surgery: a retrospective cohort study
}

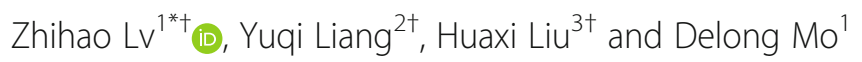

\begin{abstract}
Background: It remains controversial whether patients with Stage II colon cancer would benefit from chemotherapy after radical surgery. This study aims to assess the real effectiveness of chemotherapy in patients with stage II colon cancer undergoing radical surgery and to construct survival prediction models to predict the survival benefits of chemotherapy.

Methods: Data for stage II colon cancer patients with radical surgery were retrieved from the Surveillance, Epidemiology, and End Results (SEER) database. Propensity score matching (1:1) was performed according to receive or not receive chemotherapy. Competitive risk regression models were used to assess colon cancer causespecific death (CSD) and non-colon cancer cause-specific death (NCSD). Survival prediction nomograms were constructed to predict overall survival (OS) and colon cancer cause-specific survival (CSS). The predictive abilities of the constructed models were evaluated by the concordance indexes ( $\mathrm{C}$-indexes) and calibration curves.

Results: A total of 25,110 patients were identified, $21.7 \%$ received chemotherapy, and $78.3 \%$ were without chemotherapy. A total of 10,916 patients were extracted after propensity score matching. The estimated 3-year overall survival rates of chemotherapy were $0.7 \%$ higher than non- chemotherapy. The estimated 5-year and 10year overall survival rates of non-chemotherapy were 1.3 and $2.1 \%$ higher than chemotherapy, respectively. Survival prediction models showed good discrimination (the C-indexes between 0.582 and 0.757 ) and excellent calibration.

Conclusions: Chemotherapy improves the short-term (43 months) survival benefit of stage II colon cancer patients who received radical surgery. Survival prediction models can be used to predict OS and CSS of patients receiving chemotherapy as well as OS and CSS of patients not receiving chemotherapy and to make individualized treatment recommendations for stage II colon cancer patients who received radical surgery.
\end{abstract}

Keywords: Colon cancer, SEER, Chemotherapy, Nomogram, Competing-risk model

\footnotetext{
* Correspondence: smulzh@126.com

†Zhihao Lv, Yuqi Liang and Huaxi Liu contributed equally to this work.

'Proctology Department, Zhongshan Hospital Affiliated to Guangzhou

University of Chinese Medicine, No. 3 Kangxin Road, West District,

Zhongshan 528400, Guangdong, People's Republic of China

Full list of author information is available at the end of the article
}

(c) The Author(s). 2021 Open Access This article is licensed under a Creative Commons Attribution 4.0 International License, which permits use, sharing, adaptation, distribution and reproduction in any medium or format, as long as you give appropriate credit to the original author(s) and the source, provide a link to the Creative Commons licence, and indicate if changes were made. The images or other third party material in this article are included in the article's Creative Commons licence, unless indicated otherwise in a credit line to the material. If material is not included in the article's Creative Commons licence and your intended use is not permitted by statutory regulation or exceeds the permitted use, you will need to obtain permission directly from the copyright holder. To view a copy of this licence, visit http://creativecommons.org/licenses/by/4.0/ The Creative Commons Public Domain Dedication waiver (http://creativecommons.org/publicdomain/zero/1.0/) applies to the data made available in this article, unless otherwise stated in a credit line to the data. 


\section{Background}

Colon cancer is one of the most common malignant diseases, and it is estimated that 53,200 Americans will die from colon cancer in 2020, equivalent to more than 145 deaths per day [1]. Approximately $30-40 \%$ of colon cancer patients belong to stage II and they are recommended for radical surgery [2-4]. Although chemotherapy is widely accepted as the standard treatment for stage III colon cancer to prevent recurrence and metastasis, controversy remains over whether stage II colon cancer should receive it after radical surgery.

Both The American Society of Clinical Oncology (ASCO) clinical guidelines [5] and The European Society for Medical Oncology (ESMO) guidelines [6] recommend patients with high-risk factors to receive postoperative adjuvant chemotherapy. These high-risk factors include inadequate number of resected lymph nodes, T4 primary tumor, histology of poorly differentiated, bowel obstruction or perforation, and lymphovascular invasion. Two recent studies [7, 8] based on more than 100,000 patients, both concluded that all patients with stage II colon cancer, whether high or low risk, experienced significant improvements in overall survival (OS) associated with receiving chemotherapy, while some clinical studies showed that chemotherapy failed to improved survival $[9,10]$.

Previous studies had explored the importance of covariates in identifying prognostic, but most of them failed to clearly state whether patients underwent surgery and which type of surgery they received.

Consequently, this study aimed to construct nomograms as survival prediction models and to individualized assess the potential survival benefit of stage II colon cancer patients with chemotherapy after radical surgery.

\section{Methods}

\section{Data source}

This was a retrospective study. Data from patients with stage II colon cancer (one primary only) between 2004 and 2015 was extracted from a total of 18 cancer registries utilizing the National Cancer Institute's SEER Cancer database (1973-2016) using the SEER*Stat software version 8.3.6. We received permission to access the research data (Account Number: 20532-Nov2018) and chemotherapy information was obtained by submitting a special data request to the SEER program. This study was based on public data and permission was obtained to access this data for research only. This was not an interventional study and did not use personal identifying information. Therefore, informed consent for the study was not required. The authors have no conflicts of interest to declare. This study has been registered as a retrospective study at the Chinese Clinical Trial Registry (ChiCTR) with registration number as ChiCTR2000031512. All procedures performed in our study were in line with the STROCSS criteria [11].

\section{Patient selection}

The exclusion criteria were as follows: a) the clinicopathological information was incomplete; b) more than one primary tumor; c) unknown cause of death; d) histological type ICD-O-3, not 8140/3, 8480/3, 8481/3 and $8490 / 3$; e) no surgery or local tumor excision only; f) died within 30 days of surgery. Finally, 25,110 patients were included for analysis (Fig. 1).

Individual data retrieved for each case included age at diagnosis, sex, marital status, race, tumor site, tumor size, histology, grade, $\mathrm{T}$ stage, Number of lymph nodes (nLN), carcinoembryonic antigen (CEA), year of diagnosis, surgery classification, chemotherapy recode, cause-

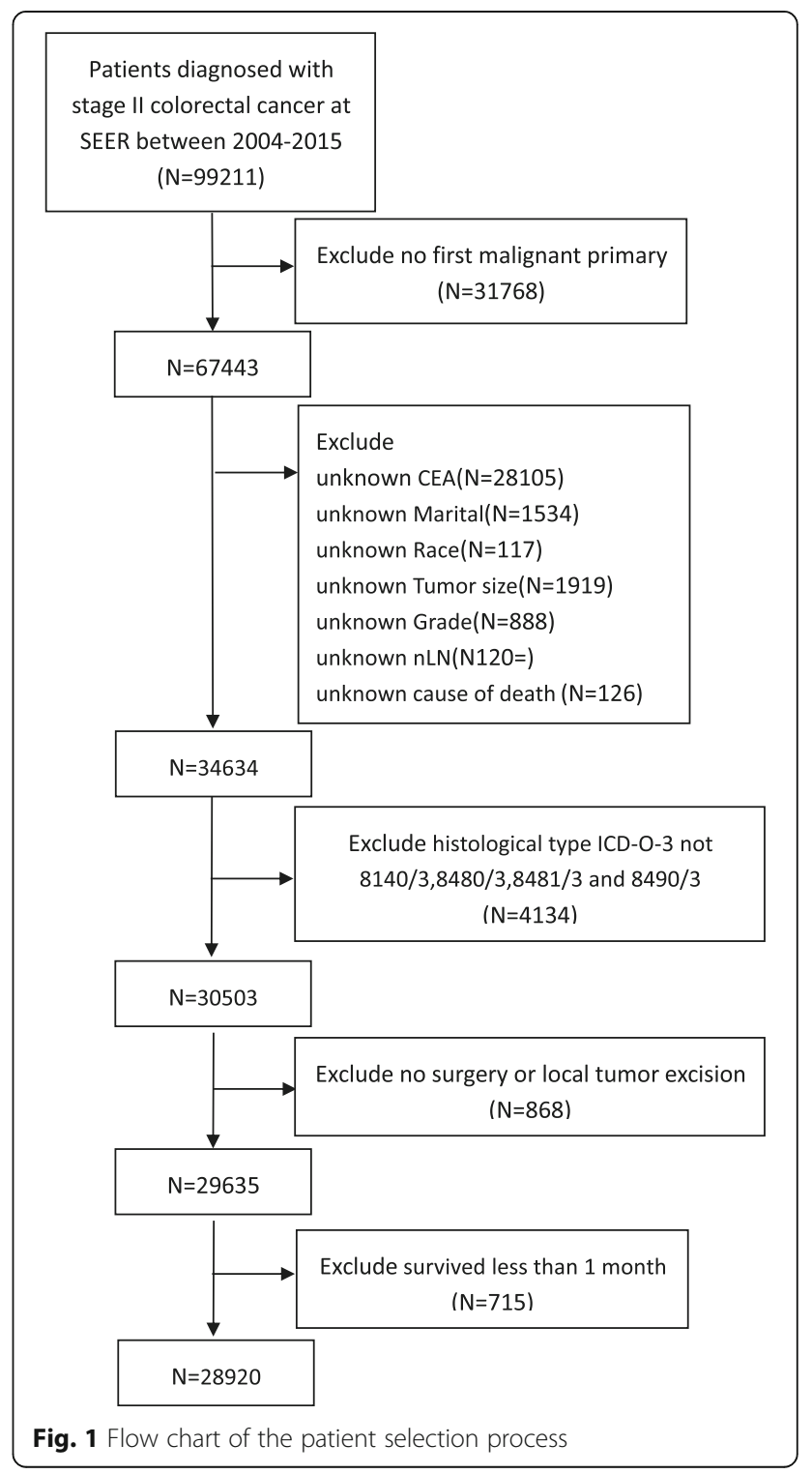


Table 1 Baseline characteristics of chemotherapy subgroups before and after propensity score matching

\begin{tabular}{|c|c|c|c|c|c|c|}
\hline Variable & $\begin{array}{l}\text { non-chemotherapy } \\
n=19,652 \text { (\%) }\end{array}$ & $\begin{array}{l}\text { Chemotherapy } \\
n=5458(\%)\end{array}$ & $p$ & $\begin{array}{l}\text { non-chemotherapy } \\
\mathrm{n}=5458 \text { (\%) (PSM) }\end{array}$ & $\begin{array}{l}\text { Chemotherapy } \\
n=5458(\%) \text { (PSM) }\end{array}$ & $p$ \\
\hline Age & & & 0.000 & & & 0.000 \\
\hline$>30$ & $57(0.3)$ & $57(1.0)$ & & $57(1.0)$ & $57(1.0)$ & \\
\hline $30-39$ & $227(1.2)$ & $284(5.2)$ & & $226(4.1)$ & $284(5.2)$ & \\
\hline $40-49$ & $1033(5.3)$ & $879(16.1)$ & & 918 (16.8) & 879 (16.1) & \\
\hline $50-59$ & $2831(14.4)$ & 1574 (28.8) & & $1640(30.0)$ & 1574 (28.8) & \\
\hline $60-69$ & $4380(22.3)$ & 1552 (28.4) & & 1407 (25.8) & $1552(28.4)$ & \\
\hline 70-79 & 5355 (27.2) & 906 (16.6) & & 871 (16.0) & 906 (16.6) & \\
\hline$\geq 80$ & 5769 (29.4) & 206 (3.8) & & $339(6.2)$ & 206 (3.8) & \\
\hline Sex & & & 0.000 & & & 0.730 \\
\hline Female & $10,282(52.3)$ & 2576 (47.2) & & $2558(46.9)$ & $2576(47.2)$ & \\
\hline Male & $9370(47.7)$ & 2882 (52.8) & & 2900 (53.1) & 2882 (52.8) & \\
\hline Marital status & & & 0.000 & & & 0.036 \\
\hline Married & $10,325(52.5)$ & 3361 (61.6) & & 3467 (63.5) & 3361 (61.6) & \\
\hline Unmarried $^{a}$ & 9327 (47.5) & 2097 (38.4) & & 1991 (36.5) & 2097 (38.4) & \\
\hline Race & & & 0.098 & & & 0.924 \\
\hline White & $15,736(80.1)$ & $4314(79.0)$ & & 4299 (78.8) & $4314(79.0)$ & \\
\hline Black & 2114 (10.8) & $643(11.8)$ & & 647 (11.9) & $643(11.8)$ & \\
\hline Other & $1802(9.2)$ & $501(9.2)$ & & $512(9.4)$ & $501(9.2)$ & \\
\hline Tumor site & & & 0.000 & & & 0.700 \\
\hline Right colon ${ }^{b}$ & $12,128(61.7)$ & $2423(44.4)$ & & 2443 (44.8) & $2423(44.4)$ & \\
\hline Left colon ${ }^{c}$ & 7524 (38.3) & 3035 (55.6) & & 3015 (55.2) & 3035 (55.6) & \\
\hline Tumor size & & & 0.000 & & & 0.007 \\
\hline$<5$ & 9649 (49.1) & $2302(42.2)$ & & $2441(44.7)$ & $2302(42.2)$ & \\
\hline$\geq 5$ & $10,003(50.9)$ & 3156 (57.8) & & 3017 (55.3) & 3156 (57.8) & \\
\hline Histology & & & 0.136 & & & 0.254 \\
\hline Adenocarcinoma & $17,172(87.4)$ & 4768 (87.4) & & 4816 (88.2) & 4768 (87.4) & \\
\hline Mucinous adenocarcinoma & $2374(12.1)$ & $648(11.9)$ & & $610(11.2)$ & $648(11.9)$ & \\
\hline Signet ring cell carcinoma & $106(0.5)$ & $42(0.8)$ & & $32(0.6)$ & $42(0.8)$ & \\
\hline Grade & & & 0.000 & & & 0.005 \\
\hline I & $1311(6.7)$ & $341(6.2)$ & & $282(5.2)$ & $341(6.2)$ & \\
\hline$\|$ & $15,192(77.3)$ & $4050(74.2)$ & & $4196(76.9)$ & $4050(74.2)$ & \\
\hline III & $2818(14.3)$ & $943(17.3)$ & & $853(15.6)$ & $943(17.3)$ & \\
\hline IV & $331(1.7)$ & $124(2.3)$ & & $127(2.3)$ & $124(2.3)$ & \\
\hline T stage & & & 0.000 & & & 0.000 \\
\hline T3 & 17,663 (89.9) & 3919 (71.8) & & 4279 (78.4) & 3919 (71.8) & \\
\hline T4 & $1989(10.1)$ & $1539(28.2)$ & & 1179 (21.6) & $1539(28.2)$ & \\
\hline$n L N^{d}$ & & & 0.000 & & & 0.064 \\
\hline 0 & $92(0.5)$ & $56(1.0)$ & & $35(0.6)$ & $56(1.0)$ & \\
\hline $1-11$ & 3507 (17.8) & $1056(19.3)$ & & $1093(20.0)$ & $1056(19.3)$ & \\
\hline$\geq 12$ & $16,053(81.7)$ & $4346(79.6)$ & & $4330(79.3)$ & $4346(79.6)$ & \\
\hline CEA $^{e}$ & & & 0.000 & & & 0.026 \\
\hline Positive & 7367 (37.5) & $2212(40.5)$ & & $2098(38.4)$ & $2212(40.5)$ & \\
\hline Negative & $12,285(62.5)$ & 3246 (59.5) & & 3360 (61.6) & $3246(59.5)$ & \\
\hline
\end{tabular}


specific death classification, vital status and survival months.

Marital status was regrouped as married or unmarried (single, widowed, divorced and separated). The tumor site was classified as the right colon (including the cecum, the ascending colon, the hepatic flexure and the transverse colon) and the left colon (including the splenic flexure and the descending, sigmoid colons and rectosigmoid junction). Number of lymph nodes (nLN) sampled was regrouped as $0,1-11, \geq 12$ and tumor size was regrouped as $<5 \mathrm{~cm}, \geq 5 \mathrm{~cm}$ according to the X-tile program [12]. The variable chemotherapy was classified as chemotherapy 'yes' or 'no/unknown' by the SEER program [13].

\section{Outcomes}

The outcomes of this study were overall survival (OS) and colon cancer cause-specific survival (CSS). OS was defined as the time from diagnosis to the date of death due to any cause. CSS was defined as the time from diagnosis to the date of death due to colon cancer. Colon cancer cause-specific death (CSD) and non-colon cancer cause-specific death (NCSD) were used in competing risk analysis. CSD was defined the same as CSS. NCSD was calculated from the time of diagnosis to the time of death due to causes other than colon cancer. Death attributed to colon cancer was regarded as the failure event. Patients who died from other causes was the competing event, and vice versa.

\section{Statistical analysis}

To mimic the randomized controlled trials and balance important patient characteristics between groups, a 1-to1 propensity score matching (PSM) method was performed with the nearest-neighbor method. Differences in distributions of chemotherapy subgroups were assessed with Chi-squared tests. Cumulative incidence was calculated by a competing risk model and a cumulative incidence plot was constructed to describe the actual prognosis of different causes of death. Univariate and multivariate cox proportional hazard models with hazard ratio (HR) and 95\% confidence interval (CI) for OS and CSS were performed. Clinicopathological variables with $p$ values $<0.05$ in the univariate analysis were selected into the multivariate analysis. The variable chemotherapy was also selected based on clinical significance, scientific knowledge and predictors identified in previously published articles [14-17]. Nomograms were constructed in R (version 3.6.2) and subjected to 1000 bootstrap resamples for internal validation. The concordance indexes (C-indexes) were calculated and calibration plots were performed to assess the predictive accuracy of OS and CSS. All statistical analyses were performed using SPSS version 25 (IBM Corporation,
Armonk, NY, USA) and $p$ values $<0.05$ were considered statistically significant.

\section{Results}

Clinical characteristics of patients and survival outcomes

A total of 25,110 patients with stage II colon cancer were included from the SEER database. The median follow-up time was 80 months (range 1-155 months). Before propensity score matching, 5458 (21.7\%) patients received chemotherapy, and 19,652 (78.3\%) patients were without chemotherapy. After propensity score matching, patients with chemotherapy were older, more often female, more often unmarried, more often White, had more often left colon cancer, had bigger tumors, presented more often with advanced $\mathrm{T}$ classification, had fewer lymph nodes and presented more often with positive CEA. The baseline characteristics of patients stratified by chemotherapy are listed in Table 1 .

\section{Cumulative incidence of death and competing risk analysis}

A total of 2334 (21.3\%) patients died, of which 1628 (69.7\%) died from colon cancer and 706 (30.2\%) died from causes other than colon cancer. The estimated 3year overall survival rates of chemotherapy were $0.7 \%$ higher than non-chemotherapy. The estimated 5-year and 10-year overall survival rates of non-chemotherapy were 1.3 and $2.1 \%$ higher than chemotherapy, respectively. The 3-, 5-, and 10-year cumulative incidence of CSD, NCSD and all cause of death are shown in Table 2. Patients with chemotherapy showed higher all cause of death, CSD, and NCSD than patients who did not

Table 2 The 3-, 5-, and 10-year cumulative incidence of CSD, NCSD and all cause of death

\begin{tabular}{llll}
\hline & $\begin{array}{l}\text { All } \\
\text { patients(\%) }\end{array}$ & \multicolumn{2}{l}{ Chemotherapy } \\
\cline { 4 - 4 } & Yes(\%) & No(\%) \\
\hline All cause of death & & 10.8 & 11.5 \\
3-Year CIF & 11.2 & 17.9 & 16.6 \\
5-Year CIF & 17.3 & 30.5 & 28.4 \\
10-Year CIF & 29.5 & & \\
CSD & & 8.7 & 8.9 \\
3-Year CIF & 8.8 & 14.0 & 12.7 \\
5-Year CIF & 13.4 & 20.1 & 19.4 \\
10-Year CIF & 19.8 & & \\
NCSD & & 2.1 & 2.6 \\
3-Year CIF & 2.4 & 3.9 & 3.9 \\
5-Year CIF & 3.9 & 10.5 & 9.1 \\
10-Year CIF & 9.8 &
\end{tabular}

${ }^{a} \mathrm{CIF}$ cumulative incidence function; ${ }^{\mathrm{b}} \mathrm{CSD}$ colon cancer cause-specific death; ${ }^{\mathrm{C}} N C S D$ non-colon cancer cause-specific death 
receive chemotherapy after 43,40 , and 52 months follow up, respectively (Fig. 2).

\section{Univariate and multivariate analyses of OS and CSS}

Univariate and multivariate cox regressions were performed to identify the variables associated with OS and CSS. In univariate survival analysis, sex showed significant association with OS, but no statistical relationship with CSS. Other variables including age, marital status, race, tumor site, tumor size, histology, grade, $\mathrm{T}$ stage, $\mathrm{nLN}$ and CEA were proved to be significantly correlated with OS and CSS $(p<0.05)$. All variables that were classified as statistically significant in univariate analysis were included in multivariate analysis and used to perform the nomogram to predict 3-, 5- and 10-year OS and CSS rates (Table 3).

\section{Nomogram}

The nomograms for chemotherapy and nonchemotherapy were built to predict 3-, 5- and 10-year OS and CSS (Figs. 3, 4). The C-indexes for chemotherapy and non-chemotherapy to predict OS were 0.711 and 0.757 , respectively ( $95 \% \mathrm{CI}, 0.697-0.725$ and $0.743-$ 0.771 ) and the C-indexes for chemotherapy and nonchemotherapy to predict CSS were 0.582 and 0.589 , respectively (95\% CI, $0.572-0.592$ and $0.579-0.599$ ). The calibration plots showed an excellent correlation
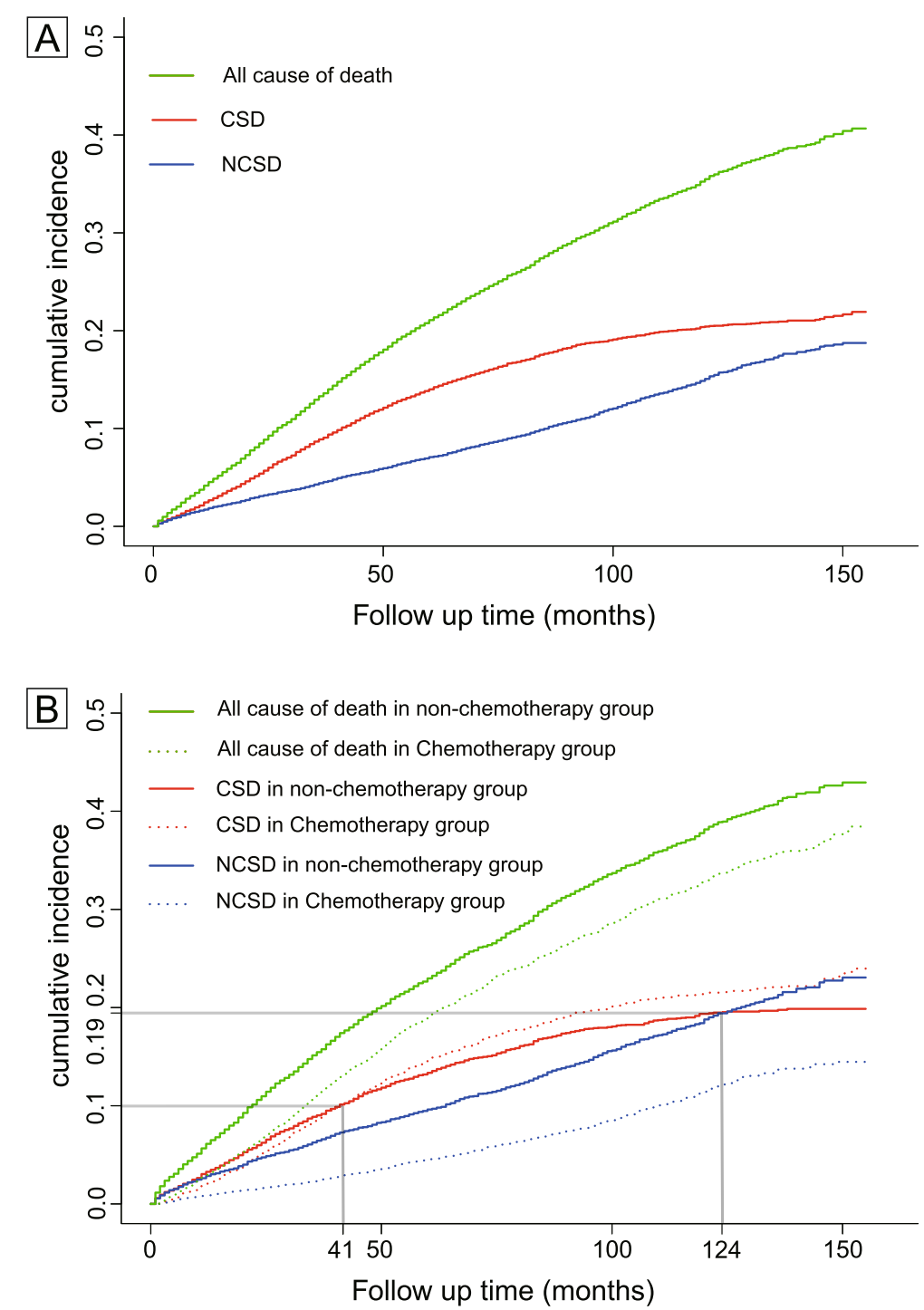

Fig. 2 Competing risk models. a: Stacked cumulative incidence plots. b: CSD, NCSD and all cause of death of receiving or not receiving chemotherapy subgroups. Patients with chemotherapy showed higher all cause of death, CSD, and NCSD than patients who did not receive chemotherapy after 43, 40, and 52 months follow up, respectively. Abbreviations: CSD, colon cancer cause-specific death; NCSD, non-colon cancer cause-specific death 
Table $\mathbf{3}$ OS and CSS in univariate and multivariate analyses

\begin{tabular}{|c|c|c|c|c|c|c|c|c|}
\hline \multirow[t]{3}{*}{ Risk factors } & \multicolumn{4}{|l|}{ os } & \multicolumn{4}{|l|}{ CSS } \\
\hline & \multicolumn{2}{|l|}{ Univariate analyses } & \multicolumn{2}{|c|}{ Multivariate analyses } & \multirow{2}{*}{$\begin{array}{l}\text { Univariate analyses } \\
\text { HR }(95 \% \mathrm{Cl})\end{array}$} & \multirow[b]{2}{*}{$p$} & \multirow{2}{*}{$\begin{array}{l}\text { Multivariate analyses } \\
\text { HR }(95 \% \mathrm{Cl})\end{array}$} & \multirow[b]{2}{*}{$p$} \\
\hline & HR (95\% Cl) & $p$ & HR $(95 \% \mathrm{Cl})$ & $p$ & & & & \\
\hline Age & & 0.000 & & & & 0.000 & & \\
\hline$>30$ & 1 & - & 1 & - & 1 & - & 1 & - \\
\hline $30-39$ & $1.71(0.77-3.77)$ & - & $1.75(0.79-3.87)$ & 0.166 & $1.39(0.63-3.11)$ & - & $1.37(0.61-3.05)$ & 0.447 \\
\hline $40-49$ & $1.86(0.88-3.96)$ & - & $1.90(0.89-4.05)$ & 0.095 & $1.48(0.69-3.15)$ & - & $1.46(0.68-3.11)$ & 0.332 \\
\hline $50-59$ & $2.55(1.21-5.38)$ & - & $2.44(1.15-5.14)$ & 0.020 & $1.94(0.92-4.10)$ & - & $1.76(0.83-3.72)$ & 0.139 \\
\hline $60-69$ & $3.80(1.80-7.99)$ & - & $3.47(1.65-7.32)$ & 0.001 & $2.63(1.24-5.54)$ & - & $2.25(1.06-4.75)$ & 0.034 \\
\hline $70-79$ & $6.63(3.15-13.96)$ & - & $5.57(2.64-11.74)$ & 0.000 & $4.07(1.93-8.60)$ & - & $3.11(1.47-6.57)$ & 0.003 \\
\hline$\geq 80$ & $12.97(6.13-27.44)$ & - & $9.96(4.70-21.10)$ & 0.000 & $7.58(3.57-16.12)$ & - & $5.14(2.41-10.95)$ & 0.000 \\
\hline Sex & & 0.024 & & & & 0.902 & & \\
\hline Female & 1 & - & 1 & - & 1 & - & - & - \\
\hline Male & $1.10(1.01-1.19)$ & - & $1.32(1.21-1.44)$ & 0.000 & $1.01(0.91-1.11)$ & - & - & - \\
\hline Marital status & & 0.000 & & & & 0.000 & & \\
\hline Married & 1 & - & 1 & - & 1 & - & 1 & - \\
\hline Unmarried $^{a}$ & $1.57(1.45-1.71)$ & - & $1.33(1.22-1.45)$ & 0.000 & $1.58(1.43-1.74)$ & - & $1.27(1.14-1.40)$ & 0.000 \\
\hline Race & & 0.000 & & & & 0.000 & & \\
\hline White & 1 & - & 1 & - & 1 & - & 1 & - \\
\hline Black & $1.29(1.15-1.45)$ & - & $1.41(1.26-1.59)$ & 0.000 & $1.41(1.23-1.61)$ & - & $1.47(1.28-1.69)$ & 0.000 \\
\hline Other & $0.73(0.62-0.86)$ & - & $0.77(0.65-0.90)$ & 0.001 & $0.86(0.71-1.03)$ & - & $0.88(0.73-1.05)$ & 0.161 \\
\hline Tumor site & & 0.048 & & & & 0.000 & & \\
\hline Right colon ${ }^{b}$ & 1 & - & 1 & - & 1 & - & 1 & - \\
\hline Left colon ${ }^{c}$ & $1.09(1.00-1.18)$ & - & $1.14(1.04-1.24)$ & 0.003 & $1.21(1.09-1.33)$ & - & $1.25(1.13-1.39)$ & 0.000 \\
\hline Tumor size & & 0.001 & & & & 0.016 & & \\
\hline$<5$ & 1 & - & 1 & - & 1 & - & 1 & - \\
\hline$\geq 5$ & $1.15(1.06-1.25)$ & - & $1.03(0.95-1.12)$ & 0.494 & $1.13(1.02-1.25)$ & - & $0.99(0.89-1.10)$ & 0.864 \\
\hline Histology & & 0.000 & & & & 0.001 & & \\
\hline Adenocarcinoma & 1 & - & 1 & - & 1 & - & 1 & - \\
\hline Mucinous adenocarcinoma & $1.14(1.01-1.28)$ & - & $0.97(0.86-1.10)$ & 0.668 & $1.14(0.99-1.32)$ & - & $1.00(0.87-1.16)$ & 0.964 \\
\hline Signet ring cell carcinoma & $2.09(1.43-3.06)$ & - & $1.34(0.91-1.98)$ & 0.138 & $2.20(1.42-3.42)$ & - & $1.45(0.92-2.28)$ & 0.105 \\
\hline Grade & & 0.000 & & & & 0.020 & & \\
\hline 1 & 1 & - & 1 & - & 1 & - & 1 & - \\
\hline$\|$ & $1.00(0.84-1.19)$ & - & $1.06(0.88-1.26)$ & 0.553 & $0.98(0.79-1.20)$ & - & $1.04(0.84-1.28)$ & 0.750 \\
\hline III & $1.19(0.98-1.45)$ & - & $1.13(0.93-1.38)$ & 0.226 & $1.15(0.92-1.45)$ & - & $1.13(0.90-1.44)$ & 0.299 \\
\hline IV & $1.54(1.14-2.08)$ & - & $1.54(1.14-2.09)$ & 0.005 & $1.33(0.92-1.92)$ & - & $1.37(0.95-1.99)$ & 0.095 \\
\hline T stage & & 0.000 & & & & 0.000 & & \\
\hline T3 & 1 & - & 1 & - & 1 & - & 1 & - \\
\hline $\mathrm{T} 4$ & $2.88(2.65-3.13)$ & - & $2.21(2.02-2.41)$ & 0.000 & $3.20(2.90-3.53)$ & - & $2.59(2.33-2.87)$ & 0.000 \\
\hline$n L N^{d}$ & & 0.000 & & & & 0.000 & & \\
\hline 0 & 1 & - & 1 & - & 1 & - & 1 & - \\
\hline $1-11$ & $0.52(0.39-0.70)$ & - & $0.56(0.41-0.75)$ & 0.000 & $0.41(0.30-0.57)$ & - & $0.48(0.34-0.66)$ & 0.000 \\
\hline$\geq 12$ & $0.31(0.23-0.42)$ & - & $0.38(0.28-0.51)$ & 0.000 & $0.25(0.19-0.35)$ & - & $0.33(0.24-0.45)$ & 0.000 \\
\hline CEA $^{e}$ & & 0.000 & & & & 0.000 & & \\
\hline Positive & 1 & - & 1 & - & 1 & - & 1 & - \\
\hline
\end{tabular}


Table 3 OS and CSS in univariate and multivariate analyses (Continued)

\begin{tabular}{|c|c|c|c|c|c|c|c|c|}
\hline \multirow[t]{3}{*}{ Risk factors } & \multicolumn{4}{|l|}{ os } & \multicolumn{4}{|l|}{ CSS } \\
\hline & \multicolumn{2}{|c|}{ Univariate analyses } & \multicolumn{2}{|c|}{ Multivariate analyses } & \multirow{2}{*}{$\begin{array}{l}\text { Univariate analyses } \\
\text { HR }(95 \% \mathrm{Cl})\end{array}$} & \multirow[b]{2}{*}{$p$} & \multirow{2}{*}{$\begin{array}{l}\text { Multivariate analyses } \\
\text { HR }(95 \% \mathrm{Cl})\end{array}$} & \\
\hline & HR $(95 \% \mathrm{Cl})$ & $p$ & HR $(95 \% \mathrm{Cl})$ & $p$ & & & & $p$ \\
\hline Negative & $0.51(0.47-0.55)$ & - & $0.62(0.57-0.67)$ & 0.000 & $0.50(0.45-0.55)$ & - & $0.62(0.56-0.69)$ & 0.000 \\
\hline
\end{tabular}

anmarried, including single, widowed, divorced and separated;

${ }^{\mathrm{b}}$ Right colon, including the cecum, the ascending colon, the hepatic flexure and the transverse colon;

'Left colon, including the splenic flexure and the descending, sigmoid colons and rectosigmoid junction;

${ }^{d} n L N$ number of lymph nodes; ${ }^{e} C E A$ carcinoembryonic antigen

between the nomogram predicted and the outcome observed (Fig. 5).

\section{Discussion}

This study constructed survival prediction nomograms that could effectively predict the OS and CSS of chemotherapy or non-chemotherapy after radical surgery for stage II colon cancer patients. The model accurately identifies patients who can benefit from chemotherapy and assists in making individual recommendations. The model is an extension of the stage grouping in the AJCC Cancer Staging Manual and can be effectively applied in clinical practice with good discrimination (the C-indexes between 0.582 and 0.757 ) and excellent calibration. Although some nomograms have been developed to predict the individual survival probability of colon cancer patients, there are still some unique features in our model [14-17]. Firstly, patients with stage II colon cancer were accurately included as the study participants based on particular chemotherapy controversy. Secondly, only patients receiving radical surgery could be included in the study to ensure homogenization. Thirdly, we included as many prognostic factors as possible based on clinical significance and statistical methods, and X-tile were used to determine the grouping of variables. Finally, in addition to overall survival, colon cancer causespecific survival was also reported to predict the individual survival probability of patients to avoid the influence of additional unmeasured confounder related to the patient's state of health.

However, although the potential survival benefit predicted by the model is an important consideration, it should not be the sole basis for decision making. Quality of life, economic conditions, and specific preferences of patients are also important factors in making treatment decisions.

Controversy exists regarding whether patients with stage II colon cancer after radical surgery should receive chemotherapy. Previous research findings were divided into three categories: a) recent studies showed chemotherapy provided a survival benefit to all stage II colon cancer patients $[7,8]$; b) another two studies reported chemotherapy did not substantially improve OS $[18,19]$; c) the QUASAR trial [20] and a pooled analysis [21] reported the survival benefits of chemotherapy only in high-risk stage II colon cancer patients, and it had confirmed by JSCCR [22], ASCO [5], NCCN [23] and ESMO [24] guidelines. This study suggests that chemotherapy improves the short-term (43 months) survival benefit of stage II colon cancer patients who received radical surgery. However, this conclusion should be treated with caution. Firstly, this study included patients since 2004 to obtain long-term follow-up data (using the TNM classification in the sixth edition of the AJCC Cancer Staging Manual), but the definition of N1c was proposed in 2010 (the TNM classification in the seventh edition of the AJCC Cancer Staging Manual). Therefore, stage II patients we included inevitably contained some stage III patients (TXN1cM0). The conclusion that patients with stage III colon cancer benefit from chemotherapy is now widely accepted $[25,26]$. Consequently, patients included in this study are more likely to be registered as positive chemotherapy results if they are mixed with unidentified stage III patients. Secondly, OS is widely accepted as the primary outcome measure in clinical studies. OS is based on the absolute risk of death without considering the specific cause of death of patients, and patients with stage II colon cancer have a long-term life expectancy. Thus, they are inevitably at high risk of NCSD. Our results show that although the risk of CSD is always higher than the risk of NCSD, both the risks are very close when the patient's expected survival time reaches 10 years or more. Therefore, the improvement in the overall survival of the chemotherapy group cannot simply be interpreted as the benefit of chemotherapy. Why, then, do patients receiving chemotherapy always have a higher risk of dying from colon cancer than from other causes. On the one hand, patients receiving chemotherapy have a better physical condition, signifying a lower risk of NCSD. On the other hand, the toxicity caused by chemotherapy improves the risk of CSD.

This study has several limitations. Firstly, some molecular biomarkers such as microsatellite instability 
A Expected OS of Chemotherapy

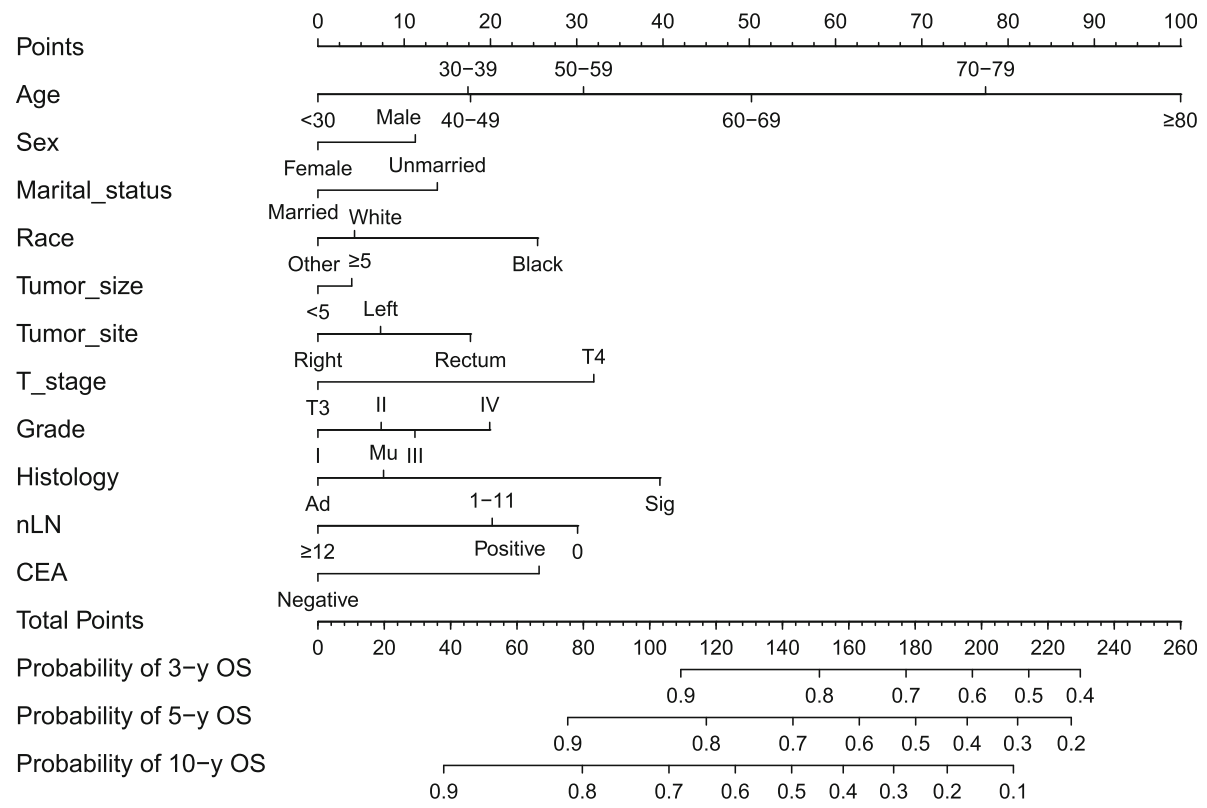

B Expected OS of non-chemotherapy

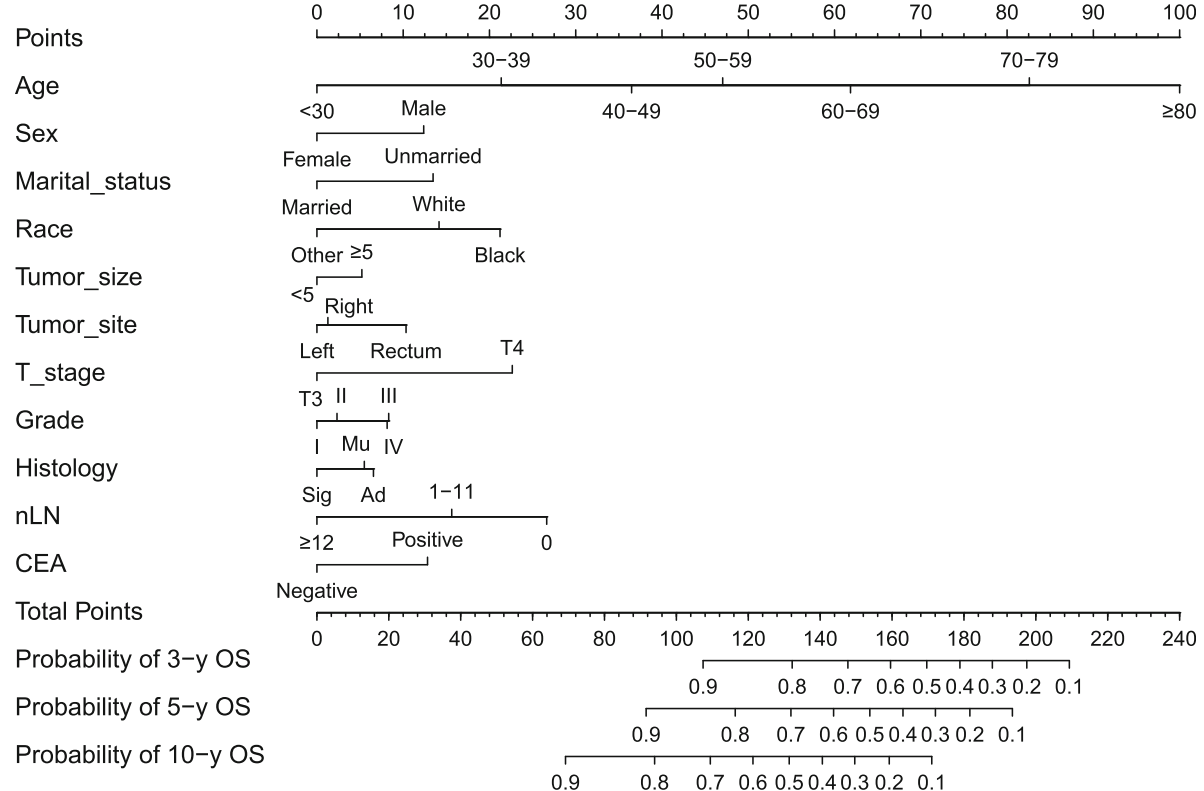

Fig. 3 Nomograms for comparing expected 3-, 5-, and 10-year overall survival (OS) with and without chemotherapy of stage II colon cancer patients received radical surgery. Abbreviations: Ad, Adenocarcinoma; Mu, Mucinous adenocarcinoma; Sig, Signet ring cell carcinoma; Right colon, including the cecum, the ascending colon, the hepatic flexure and the transverse colon; Left colon, including the splenic flexure and the descending, sigmoid colons and rectosigmoid junction; nLN, number of lymph nodes; CEA, carcinoembryonic antigen

(MSI) and BRAF mutations that could affect the prognosis of stage II colon cancer were not included in our analysis, which might lead to a certain degree of bias [27]. Secondly, the chemotherapy information in SEER database inevitably causes a confounding bias $(72.1 \%$ sensitivity according to studies) [13]; for example, the chemotherapy record in SEER database is classified as "No/Unknown" and "Yes". Although we obtained data of 


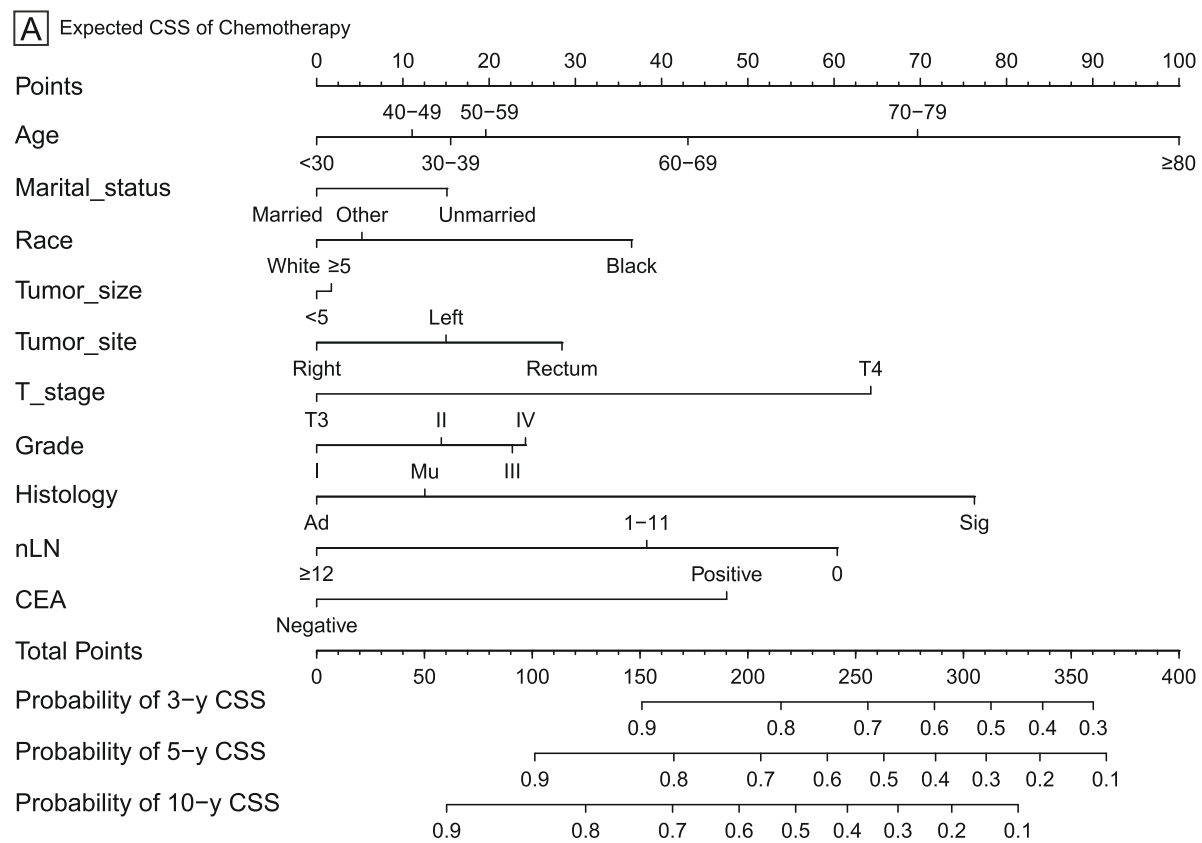

B Expected CSS of non-chemotherapy

Points
Age
Marital_status
Race
Tumor_size
Tumor_site
T_stage
Grade
Histology
nLN
CEA
Total Points
Probability of 3-y CSS
Probability of 5-y CSS
Probability of 10-y CSS

Fig. 4 Nomograms for comparing expected 3-, 5-, and 10-year colon cancer cause-specific survival (CSS) with and without chemotherapy of stage II colon cancer patients received radical surgery. Abbreviations: Ad, Adenocarcinoma; Mu, Mucinous adenocarcinoma; Sig, Signet ring cell carcinoma; Right colon, including the cecum, the ascending colon, the hepatic flexure and the transverse colon; Left colon, including the splenic flexure and the descending, sigmoid colons and rectosigmoid junction; nLN, number of lymph nodes; CEA, carcinoembryonic antigen

5458 patients with definite chemotherapy from SEER database, we don't know whether the patients recorded as "No/Unknown" actually received chemotherapy. Thirdly, we simply compared the chemotherapy group with the non-chemotherapy group and did not distinguish different chemotherapy regimens. Finally, this is a retrospective study that may introduce inherent selection bias.

\section{Conclusions}

We develop a survival prediction model to estimate individual net survival benefit of chemotherapy in patients 

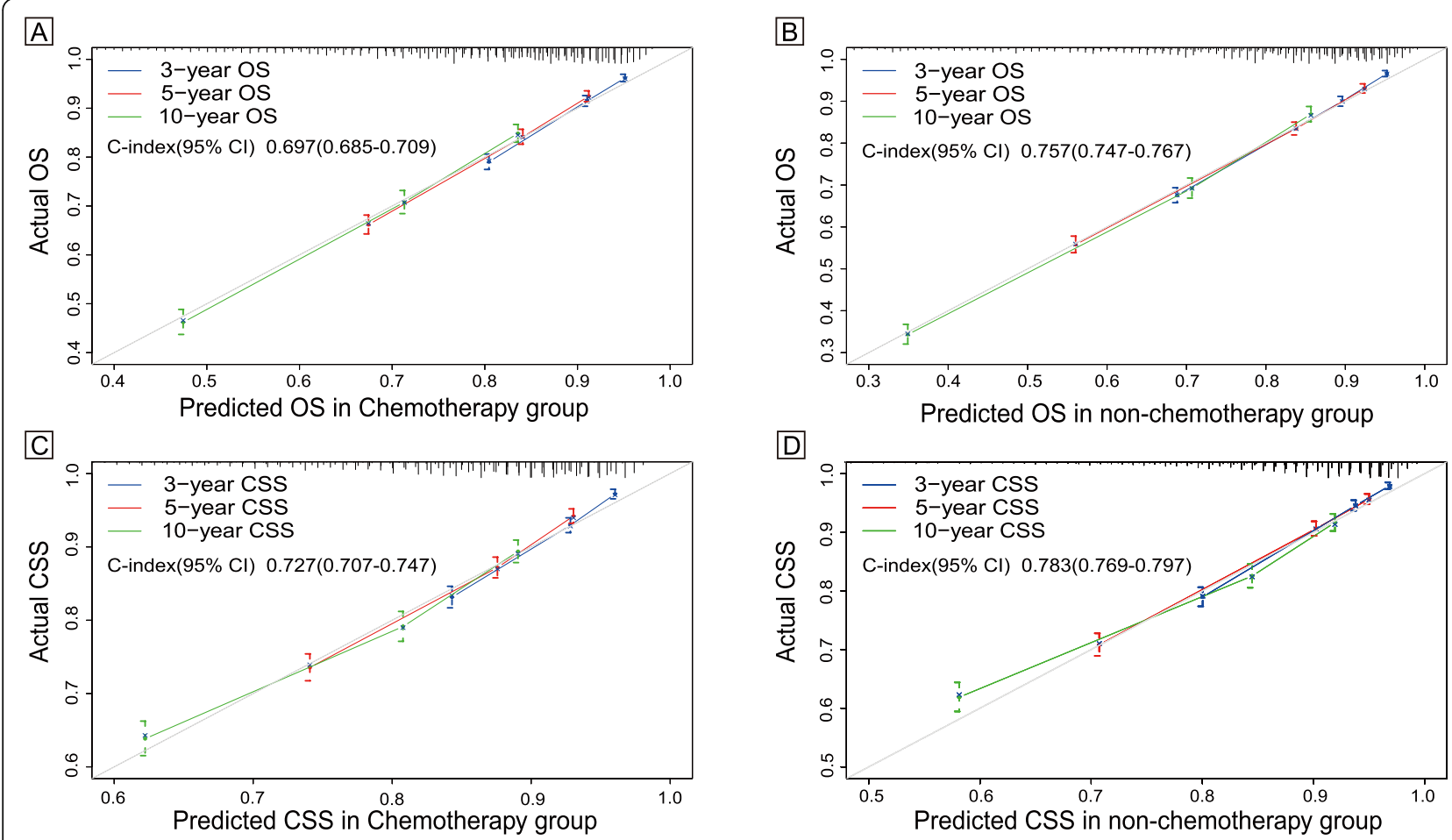

Fig. 5 Calibration curve of the nomograms. a: 3-, 5-, and 10-year OS nomogram calibration curves of the chemotherapy group. b: 3-, 5-, and 10year OS nomogram calibration curves of the non-chemotherapy group. c: 3-, 5-, and 10-year CSS nomogram calibration curves of the chemotherapy group. d: 3-, 5-, and 10-year CSS nomogram calibration curves of the non-chemotherapy group. Abbreviations: OS, overall survival; CSS, colon cancer cancer-specific survival

with stage II colon cancer after radical surgery. To the best of our knowledge, these nomograms are the first survival prediction models to predict the survival benefit of chemotherapy in stage II colon cancer patients after radical surgery using both OS and CSS outcome measures. This model can help clinicians to quantify the benefits of chemotherapy after radical surgery of stage II colon cancer patients and to make personalized treatment recommendations and decisions.

\section{Abbreviations}

SEER: Surveillance, Epidemiology, and End Results; PSM: Propensity score matching; CSD: Colon cancer cause-specific death; NCSD: Non-colon cancer cause-specific death; OS: Overall survival; CSS: Colon cancer cause-specific survival; C-indexes: Concordance indexes; HR: Hazard ratio; Cl: Confidence interval

\section{Acknowledgements}

Not applicable.

\section{Authors' contributions}

ZL: Study design, data collections, data analysis, and writing. YL: Study design, data collections, data analysis, and writing. HL: Data collections, data analysis, and writing. DM: Data collections, data analysis. All authors have read and approved the manuscript.

\section{Funding}

No funding was received for this study.
Availability of data and materials

The data used in this study are available free of charge online at www.seer. cancer.gov on request.

\section{Declarations}

\section{Ethics approval and consent to participate}

All procedures performed in study involving human participants were in accordance with the ethical standards of the institutional and/or national research committee and with the 1964 Helsinki Declaration and its later amendments or comparable ethical standards. The SEER Program collects data from population-based cancer registries with anonymous information. The SEER is a publicly available database, thus no ethical approval is required.

Consent for publication

Not applicable.

\section{Competing interests}

The authors declare that they have no competing interests.

\section{Author details}

'Proctology Department, Zhongshan Hospital Affiliated to Guangzhou University of Chinese Medicine, No. 3 Kangxin Road, West District, Zhongshan 528400, Guangdong, People's Republic of China. ${ }^{2}$ Science and Technology Innovation Center, Guangzhou University of Chinese Medicine, Guangzhou, Guangdong, People's Republic of China. ${ }^{3}$ College of Traditional Chinese Medicine, Southern Medical University, Guangzhou, Guangdong, People's Republic of China. 
Received: 19 November 2020 Accepted: 17 March 2021

Published online: 23 March 2021

\section{References}

1. Siegel RL, Miller KD, Jemal A. Cancer statistics, 2020. CA Cancer J Clin. 2020; 70(1):7-30. https://doi.org/10.3322/caac.21590.

2. Jessup JM, Menck HR, Winchester DP, Hundahl SA, Murphy GP. The National Cancer Data Base report on patterns of hospital reporting. Cancer. 1996; 78(8):1829-37. https://doi.org/10.1002/(sici)1097-0142(19961015)78:8<1829:a id-cncr26>3.0.co;2-z.

3. O'Connell JB, Maggard MA, Ko CY. Colon cancer survival rates with the new American joint committee on Cancer sixth edition staging. J Natl Cancer Inst. 2004:96(19):1420-5. https://doi.org/10.1093/jnci/djh275.

4. Dekker E, Tanis PJ, Vleugels JLA, Kasi PM, Wallace MB. Colorectal cancer. Lancet. 2019;394(10207):1467-80. https://doi.org/10.1016/s0140-6736(1 9)32319-0.

5. Benson AB 3rd, Schrag D, Somerfield MR, et al. American Society of Clinical Oncology recommendations on adjuvant chemotherapy for stage II colon cancer. J Clin Oncol. 2004;22(16):3408-19. https://doi.org/10.1200/JCO.2004. 05.063 .

6. Labianca R, Nordlinger B, Beretta GD, et al. Early colon cancer: ESMO clinical practice guidelines for diagnosis, treatment and follow-up. Ann Oncol 24 Suppl 6:vi64-72. 2013. https://doi.org/10.1093/annonc/mdt354.

7. Casadaban L, Rauscher G, Aklilu M, Villenes D, Freels S, Maker AV. Adjuvant chemotherapy is associated with improved survival in patients with stage ॥ colon cancer. Cancer. 2016;122(21):3277-87. https://doi.org/10.1002/cncr.301 81.

8. Simillis $\mathrm{C}$, Singh $\mathrm{H}$, Afxentiou $\mathrm{T}$, et al. Postoperative chemotherapy improves survival in patients with resected high-risk stage II colorectal cancer: results of a systematic review and meta-analysis. Color Dis. 2020;22(10):1231-44. https://doi.org/10.1111/codi.14994.

9. Matsuda C, Ishiguro M, Teramukai S, Kajiwara Y, Fujii S, Kinugasa Y, Nakamoto Y, Kotake M, Sakamoto Y, Kurachi K, Maeda A, Komori K, Tomita N, Shimada Y, Takahashi K, Kotake K, Watanabe M, Mochizuki H, Nakagawa Y, Sugihara K, SACURA Study Group. A randomised-controlled trial of 1-year adjuvant chemotherapy with oral tegafur-uracil versus surgery alone in stage II colon cancer: SACURA trial. Eur J Cancer. 2018;96:54-63. https://doi. org/10.1016/j.ejca.2018.03.009.

10. Booth CM, Nanji S, Wei X, Peng Y, Biagi JJ, Hanna TP, Krzyzanowska MK, Mackillop WJ. Adjuvant chemotherapy for stage II Colon Cancer: practice patterns and effectiveness in the general population. Clin Oncol. 2017;29(1): e29-38. https://doi.org/10.1016/j.clon.2016.09.001.

11. Agha R, Abdall-Razak A, Crossley E, Dowlut N, losifidis C, Mathew G, Beamishaj, Bashashati M, Millham FH, Orgill DP, Noureldin A, Nixon IJ, Alsawadi A, Bradley PJ, Giordano S, Laskin DM, Basu S, Johnston M, Muensterer OJ, Mukherjee I, Ngu JCY, Valmasoni M, Pagano D, Vasudevan B, Rosin RD, McCaul JA, Albrecht J, Hoffman JR, Thorat MA, Massarut S, Thoma A, Kirshtein B, Afifi RY, Farooq N, Challacombe B, Pai PS, Perakath B, Kadioglu H, Aronson JK, Raveendran K, Machado-Aranda D, Klappenbach R, Healy D, Miguel D, Leles CR, Ather MH. STROCSS 2019 guideline: strengthening the reporting of cohort studies in surgery. Int J Surg. 2019;72: 156-65. https://doi.org/10.1016/j.ijsu.2019.11.002.

12. Camp RL, Dolled-Filhart M, Rimm DL. X-tile: a new bio-informatics tool for biomarker assessment and outcome-based cut-point optimization. Clin Cancer Res. 2004;10(21):7252-9. https://doi.org/10.1158/1078-0432.CCR-040713

13. Noone AM, Lund JL, Mariotto A, Cronin K, McNeel T, Deapen D, Warren JL. Comparison of SEER treatment data with Medicare claims. Med Care. 2016; 54(9):e55-64. https://doi.org/10.1097/mlr.0000000000000073.

14. Zhou Z, Mo S, Dai W, Xiang W, Han L, Li Q, Wang R, Liu L, Zhang L, Cai S, Cai G. Prognostic nomograms for predicting cause-specific survival and overall survival of stage I-III colon cancer patients: a large population-based study. Cancer Cell Int. 2019;19(1):355. https://doi.org/10.1186/s12935-019-1 079-4.

15. Liu J, Huang X, Yang W, Li C, Li Z, Zhang C, Chen S, Wu G, Xie W, Wei C, Tian $C$, Huang $L$, Jeen F, Mo X, Tang W. Nomogram for predicting overall survival in stage II-III colorectal cancer. Cancer Med. 2020;9(7):2363-71. https://doi.org/10.1002/cam4.2896.

16. Wang $Y$, Wu J, He H, Ma H, Hu L, Wen J, Lyu J. Nomogram predicting cancer-specific mortality in early-onset rectal cancer: a competing risk analysis. Int J Color Dis. 2020;35(5):795-804. https://doi.org/10.1007/s00384020-03527-9.

17. Zheng P, Lai C, Yang W, Guo J, Xiao S, Chen Z. Nomogram predicting cancer-specific survival in elderly patients with stages I-III colon cancer. Scand J Gastroenterol. 2020;55(2):202-8. https://doi.org/10.1080/00365521.2 020.1720280 .

18. Fu J, Wu L, Ge C, Xu T, Li D, Fu W, Wang L, du J. De-escalating chemotherapy for stage II colon cancer? Ther Adv Gastroenterol. 2019;12: 1756284819867553. https://doi.org/10.1177/1756284819867553.

19. O'Connor ES, Greenblatt DY, LoConte NK, et al. Adjuvant chemotherapy for stage II colon cancer with poor prognostic features. J Clin Oncol. 2011; 29(25):3381-8. https://doi.org/10.1200/JCO.2010.34.3426.

20. Group QC. Adjuvant chemotherapy versus observation in patients with colorectal cancer: a randomised study. Lancet. 2007;370(9604):2020-9. https://doi.org/10.1016/S0140-6736(07)61866-2.

21. Labianca R, Pancera G, Torri V, Zaniboni A, Erlich-man CMS. Efficacy of adjuvant fluorouracil and folinic acid in colon cancer. International multicentre pooled analysis of Colon Cancer trials (IMPACT) investigators. Lancet. 1995;345:939-44.

22. Hashiguchi Y, Muro K, Saito Y, et al. Japanese Society for Cancer of the Colon and Rectum (JSCCR) guidelines 2019 for the treatment of colorectal cancer. Int J Clin Oncol. 2020;25(1):1-42. https://doi.org/10.1007/s10147-01901485-z.

23. Benson 3rd AB, Venook AP, Cederquist $L$, et al (2017) Colon Cancer, Version 1.2017, NCCN clinical practice guidelines in oncology. J Natl Compr Cancer Netw 15:370-398. https://doi.org/10.6004/jnccn.2017.0036, 3.

24. Schmoll HJ, Van Cutsem E, Stein A, et al. ESMO consensus guidelines for management of patients with colon and rectal cancer. A personalized approach to clinical decision making. Ann Oncol. 2012;23(10):2479-516. https://doi.org/10.1093/annonc/mds236.

25. Shah MA, Renfro LA, Allegra CJ, André T, de Gramont A, Schmoll HJ, Haller DG, Alberts SR, Yothers G, Sargent DJ. Impact of patient factors on recurrence risk and time dependency of Oxaliplatin benefit in patients with Colon Cancer: analysis from modern-era adjuvant studies in the adjuvant Colon Cancer end points (ACCENT) database. J Clin Oncol. 2016;34(8):84353. https://doi.org/10.1200/jco.2015.63.0558.

26. Andre T, de Gramont A, Vernerey D, et al. Adjuvant fluorouracil, Leucovorin, and Oxaliplatin in stage II to III Colon Cancer: updated 10-year survival and outcomes according to BRAF mutation and mismatch repair status of the MOSAIC study. J Clin Oncol. 2015;33(35):4176-87. https://doi.org/10.1200/ JCO.2015.63.4238

27. Lochhead P, Kuchiba A, Imamura Y, Liao X, Yamauchi M, Nishihara R, Qian ZR, Morikawa T, Shen J, Meyerhardt JA, Fuchs CS, Ogino S. Microsatellite instability and BRAF mutation testing in colorectal cancer prognostication. J Natl Cancer Inst. 2013;105(15):1151-6. https://doi.org/10.1093/jnci/djt173.

\section{Publisher's Note}

Springer Nature remains neutral with regard to jurisdictional claims in published maps and institutional affiliations.

Ready to submit your research? Choose BMC and benefit from

- fast, convenient online submission

- thorough peer review by experienced researchers in your field

- rapid publication on acceptance

- support for research data, including large and complex data types

- gold Open Access which fosters wider collaboration and increased citations

- maximum visibility for your research: over $100 \mathrm{M}$ website views per year

At $\mathrm{BMC}$, research is always in progress.

Learn more biomedcentral.com/submissions 